\title{
AXIOMATIC-DESIGN SCHEDULING METHOD FOR FAST-TRACK CONSTRUCTION
}

\author{
Min-Yuan Cheng \\ Professor \\ Department of Construction Engineering, National \\ Taiwan University Of Science And Technology \\ \#43,Sec.4,Keelung Rd.,Taipei,106,Taiwan,R.O.C \\ myc@mail.ntust.edu.tw
}

\author{
Ming-Hsiu Tsai \\ Postdoctoral researcher, \\ Department of Construction Engineering, National \\ Taiwan University Of Science And Technology \\ \#43,Sec.4,Keelung Rd.,Taipei,106,Taiwan,R.O.C \\ mht@mail.ntust.edu.tw
}

\begin{abstract}
The fast-tracking delivery method has received considerable attention over the last decade because of its time saving feature depending on overlapping of phases of a project. However, to implement the fast-tracking construction, not only the overlapping relationship between design and construction phases, but also the estimating the reduction of the construction duration is difficult to determine. Therefore, this study applies the Axiomatic Design (AD) approach to develop a fast-track scheduling method for design-build project to decompose a project into work packages and further to determine the overlap relationships between work packages. Consequently, based on the determined overlap relationships, the fast-track schedule can be subsequently constructed finally.
\end{abstract}

\section{KEYWORDS}

Fast-Track Construction, Design-Build, Overlap, Project Scheduling, Axiomatic Design (AD)

\section{INTRODUCTION}

Under a rapidly changing business environment, the fast-tracking delivery method has received considerable attention over the last decade because of its time saving feature depending on overlapping of phases of a project. Therefore, D/B is considered to be the fastest project delivery system as it encourages fast-tracking of design and construction phases. However, to implement the fast-tracking construction, not only the overlapping relationship between design and construction phases is difficult to determine, but the conditions of the resource allocation are also complex to evaluate. Thus, the schedule plan of the fast-tracking construction can not be done easily for most $\mathrm{D} / \mathrm{B}$ project managers. Meanwhile, due to the difficulty in estimating the reduction of the construction duration, the feasibility and the usability of the fast-tracking construction is decreased. Therefore, the purpose of this study is developing a fast-tracking scheduling method for project managers to construct a fast-tracking network for a $\mathrm{D} / \mathrm{B}$ project.

Few papers related to the fast-track construction scheduling were addressed. Peña-Mora and $\mathrm{Li}$ [1]combined axiomatic design, concurrent engineer, the graphical evaluation and review technique, and system dynamics to propose a dynamic planning and control methodology (DPM) for discovering the potential problems of fast-tracking projects. Moreover, Maheswari and Varghese [2] utilized the dependency structure matrix (DSM) to estimate the natural overlap project duration. The communication time was a new concept addressed in the Maheswari and 
Varghese's paper while estimating the normal project duration. Generally, these papers aimed at estimating overlap degrees of two activities to be a reference for creating a construction schedule. Differing from these papers, this study tried to decompose a $\mathrm{D} / \mathrm{B}$ project into work packages including a couple of design and construction jobs; therefore, the overlap between work packages could be a new concept to reduce the projection duration. To this target, the Axiomatic Design (AD) methodology was applied in this paper.

Axiomatic design provides a framework for describing design objects that are consistent for all types of design problems and at all levels of detail. Thus, different designers can quickly understand the relationships between the intended functions of an object and the means by which they are achieved. Since its first introduction, AD has been successfully applied to computer applications [3][4], manufacturing [5], structural design [6], decision support systems [7], and other areas. By using the axiomatic design methodology, a $\mathrm{D} / \mathrm{B}$ project can be decomposed to be several design-build packages which respectively consist of a specific pair of design and construction activities, and the overlapping relationships among all design-build packages can be revealed according to the dependence matrices. Once the overlapping relationships of design and construction activities were determined, not only the fast-tracking network can be subsequently generated, but the project duration can also be calculated to evaluate the time benefit of the fast-track construction.

\section{AXIOMATIC DESIGN APPROACH FOR OVERLAP ANALYSIS}

Based on the AD methodology, this study maps a $\mathrm{D} / \mathrm{B}$ project into customer, functional, physical and process domains by zigzagging decomposition and creating dependency matrices. Figure 1 shows AD mapping relationships. Each associated domain consists of specific characteristic vectors such as customer need $\{\mathrm{CN}\}$, functional requirement $\{\mathrm{FR}\}$, design proposal $\{\mathrm{DP}\}$ and construction activity $\{\mathrm{CA}\}$.

Concurrently, the design matrix $[\mathrm{A}]$ between $\{\mathrm{FR}\}$ and $\{\mathrm{DP}\}$ vectors and the construction matrix $[\mathrm{B}]$ between $\{D P\}$ and $\{C A\}$ vectors can be evaluated to present the dependences of DPs and CAs. The process of mapping between FRs and DPs allows the dependency relationships between FRs to be expressed mathematically in terms of characteristic vectors defining the functional contribution value of DPs to each FR. The relationship between $\{F R$ \} and $\{\mathrm{DP}\}$ can be written as:

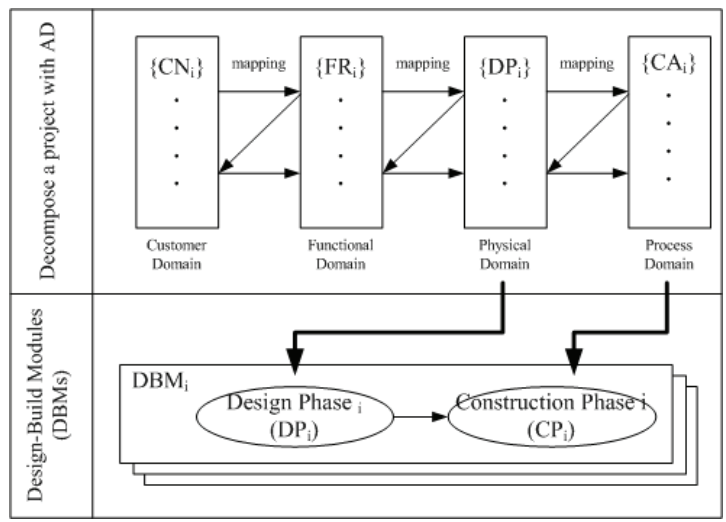

Figure 1 Relation Between the AD Method and Design-Build Package (DBP)

$\{F R\}=[A]\{D P\}$

In Equation (1), [A] expresses the functional contribution values of design proposals to each FR. After referencing the contribution relationships within this matrix [A], dependency relationships between FRs can be determined by clustering their related DPs. Similarly, Equation (2) shows the mathematical relationship of $\{D P\}$ and $\{C A\}$. The matrix [B] is defined as a construction matrix representing the dependent relationship between DPs and CAs concurrency.

$\{D P\}=[B]\{C A\}$

Meanwhile, to reduce the complexity raised by overlapping between design and construction activities, the relationship between FRs must satisfy the Independence Axiom. That is, the design matrix [A] must either be a diagonal or triangular matrix (as shown in Figure 2(2) and 2(3)). Therefore, by utilizing the AD methodology, engineers can determine the sequence of DPs and CAs in accordance with the matrix type of the matrix $[\mathrm{A}]$ and $[\mathrm{B}]$. 


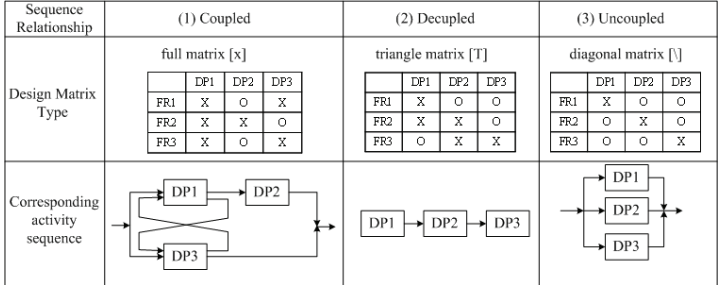

Figure 2 Three Types of Design Matrices of Axiomatic Design Method (Peña-Mora and Li 2001)

Further, to make fast-track possible, this study packages a DP and its corresponding $\mathrm{CA}$ into a design-build package(i) (DBPi) as shown in Figure 1 , so that dependency relationships among DBPs can be determined based on matrices [A] and [B]. To this aim, the concurrent matrix $[\mathrm{C}]$ is applied to summarize the overlapping relationships of DPs and CAs. As Equation (3) shows, matrix [C] is the cross product of matrix [A] and [B].

$$
[C]=[A][B] ; C_{i k}=\sum_{j} A_{i j} B_{j k}
$$

where $C_{i k} \in[C], A_{i j} \in[A]$, and $B_{j k} \in[B]$.

Accordingly, a mathematical relationship, as shown in Equation 4 exists between FR, DP, CA, and DBP.

$D B M_{i}=\frac{F R_{i}}{C P V_{i}}=\sum_{k} C_{i k} \frac{C P V_{k}}{C P V_{i}}=\sum_{j} \sum_{k} A_{i j} B_{j k} \frac{C P V_{k}}{C P V_{i}}=\sum_{j} \sum_{k} \frac{\partial F R_{i}}{\partial D P_{j}} \frac{\partial D P_{j}}{\partial C P V_{k}} \frac{C P V_{k}}{C P V_{i}}$

As illustrated in Equation (4), DBP represents the interrelationships between all $\mathrm{CA}_{\mathrm{i}}$ through the $\mathrm{C}_{\mathrm{ik}}$ term. Also, due to the combination of interrelationships between DPs and CAs in the $\mathrm{C}_{\mathrm{ik}}$, a DBPi combines not only the direct incremental relationship between $\mathrm{FR}_{\mathrm{i}}$ and $\mathrm{CA}_{\mathrm{i}}$, but also the interrelationships among $\mathrm{DP}_{\mathrm{i}}, \mathrm{CA}_{\mathrm{i}}$ and $\mathrm{CA}_{\mathrm{k}}$. Meanwhile, to reduce the complexity raised by the overlapping of DBPs, no overlap between the DP and CA in the same DBP is encouraged. Table 1 illustrates the dependent relationships between $\mathrm{DBP}_{\mathrm{i}}$ and $\mathrm{DBP}_{\mathrm{k}}$.

Consequently, a project can be decomposed to be DBPs which include their specific design and construction works, and the overlapping relationships between DBPs can determined simultaneously.
Table 1 Overlap Relationships Between Two Design-Build Packages (Cheng and Tsai 2005)

\begin{tabular}{|c|c|c|c|c|c|c|c|}
\hline \multirow{2}{*}{$\begin{array}{c}\text { Type } \\
\text { (equence } \\
\text { symbol) }\end{array}$} & \multicolumn{3}{|c|}{ Matrix type } & \multirow{2}{*}{\multicolumn{3}{|c|}{ Overlap Relationship }} & \multirow[t]{2}{*}{ Description } \\
\hline & {$[\mathbf{A}]$} & {$[\mathbf{B}]$} & {$[\mathrm{C}]$} & & & & \\
\hline \multirow{2}{*}{$\begin{array}{c}1 \\
(\mathrm{PP})\end{array}$} & \multirow{2}{*}{ [] } & \multirow{2}{*}{ [] } & \multirow{2}{*}{ []] } & $D P M_{i}$ & Design $_{i}$ & $\rightarrow$ Construction $_{i}$ & \multirow{2}{*}{$\begin{array}{l}\text { Parallel Design } \\
\text { \& Parallel } \\
\text { Construction: }\end{array}$} \\
\hline & & & & $\mathrm{DBM}_{k}$ & Desiggn $_{k}$ & $\rightarrow$ Consiruction $_{k}$ & \\
\hline \multirow{2}{*}{$\begin{array}{c}2 \\
\text { (PC) }\end{array}$} & \multirow{2}{*}{ [l] } & \multirow{2}{*}[\mathrm{LT}]{} & \multirow{2}{*}{ [LT] } & $\mathrm{DBM}_{\mathrm{i}}$ & Design $_{i}$ & $\rightarrow$ Construction $n_{i}$ & \multirow{2}{*}{$\begin{array}{l}\text { Parallel Design } \\
\& \text { Continuous } \\
\text { Construction : }\end{array}$} \\
\hline & & & & $\mathrm{DBM}_{\mathrm{k}}$ & Design $\mathrm{k}$ & $\rightarrow$ Construction $\mathrm{K}_{\mathrm{K}}$ & \\
\hline \multirow{2}{*}{$\begin{array}{c}3 \\
(\mathrm{CP})\end{array}$} & [LT] & \multirow{2}{*}{ [] } & {$[\mathrm{LT}]$} & & Design $_{i}$ & $\rightarrow$ Consitruclion; & \multirow{2}{*}{$\begin{array}{l}\text { Continuous } \\
\text { Desion \& } \\
\text { Parallel } \\
\text { Construction : }\end{array}$} \\
\hline & [UT] & & [UT] & $\mathrm{DPM}_{2} \rightarrow$ & $\operatorname{Design}_{k}$ & $\rightarrow$ Consisuction $_{\mathrm{k}}$ & \\
\hline \multirow{2}{*}{$\begin{array}{c}4 \\
\text { (CC) }\end{array}$} & {$[\mathrm{LT}]$} & {$[\mathrm{LT}]$} & {$[\mathrm{LT}]$} & $\mathrm{DBM}_{i}$ & $\operatorname{Design}_{\mathrm{i}}$ & $\rightarrow$ Construction $_{\mathrm{i}}$ & \multirow{2}{*}{$\begin{array}{l}\text { Continuous } \\
\text { Design \& } \\
\text { Continuous } \\
\text { Construction : }\end{array}$} \\
\hline & [UT] & [UT] & [UT] & $\mathrm{DBM}_{\mathrm{k}}$ & Design : & 1, Construction $k$ & \\
\hline \multirow{2}{*}{$\begin{array}{c}5 \\
(\mathrm{PF})\end{array}$} & \multirow[b]{2}{*}{ [l] } & \multirow{2}{*}[\mathrm{X}]{} & \multirow{2}{*}[\mathrm{X}]{} & $\mathrm{DFM}_{\mathrm{i}}$ & Designin $_{i}$ & $\rightarrow$ Construcion $_{4}$ & \multirow{2}{*}{$\begin{array}{l}\text { Parallel Design } \\
\text { \& Feedback } \\
\text { Construction: }\end{array}$} \\
\hline & & & & $\mathrm{DPBM}_{k}$ & $\operatorname{Design}_{k}$ & $\rightarrow$ Consitruction $_{k}$ & \\
\hline \multirow{2}{*}{$\begin{array}{c}6 \\
\left(\mathrm{CC}_{b}\right)\end{array}$} & [LT] & [UT] & \multirow[b]{2}{*}[\mathrm{X}]{} & $\mathrm{DBM}_{\mathrm{i}}$ & $D_{\text {Design }} n_{4}$ & If Construction: & \multirow{2}{*}{$\begin{array}{l}\text { Continuous } \\
\text { Design \& } \\
\text { Backward } \\
\text { Continuous } \\
\text { Construction : }\end{array}$} \\
\hline & $\begin{array}{l}\text { or } \\
\text { [UT] }\end{array}$ & $\begin{array}{l}\text { or } \\
{[\mathrm{LT}]}\end{array}$ & & $\mathrm{DEM}_{\mathrm{k}}$ & Design $_{t}$ & $\rightarrow C_{1}$ & \\
\hline \multirow{2}{*}{$\begin{array}{c}7 \\
\text { (CF) }\end{array}$} & [LT] & \multirow{2}{*}[\mathrm{X}]{} & \multirow[b]{2}{*}[\mathrm{X}]{} & $\mathrm{DBM}_{i}$ & Desigen $_{i}$ & $\rightarrow C_{\text {Construcion }}$ & \multirow{2}{*}{$\begin{array}{l}\text { Continuous } \\
\text { Design \& } \\
\text { Feedback } \\
\text { Construction }\end{array}$} \\
\hline & $\begin{array}{l}\text { or } \\
\text { [UT] }\end{array}$ & & & $\mathrm{DPM}_{2}-$ & Design $_{k}$ & $\rightarrow$ Cansitruction $_{k}$ & \\
\hline
\end{tabular}

Denotation: $[\backslash]$ diagonal matrix, $[\mathrm{LT}]$ lower triangular matrix, $[\mathrm{UT}]$ upper triangular matrix, $[\mathrm{X}]$ full matrix.

\section{AXIOMATIC DESIGN SCHEDULING METHOD}

Combining the $\mathrm{AD}$ overlapping analysis approach and network scheduling method, a proposed scheduling method for fast-track construction is illustrated as Figure 3 shows.

\subsection{Design Activities Analysis}

In this phase, the necessary DPs of a D/B project needs to be derived previously from the owner's needs; subsequently, the design sequence of DPs can be analyzed in accordance with the DPs' design matrix [A] which represents the independence relationships between all DPs. Tis study applied the zigzagging decomposition procedure as shown in Figure 4 to create FRs and DPs hierarchies.

After the FRs in the current level are generated, their corresponding DPs can be determined, and the design matrix corresponding to this level can be evaluated to ensure the DPs within the current level satisfy the Independence Axiom. Table 2 
shows the design matrix of FR21 and DP21 which is a lower triangle matrix.

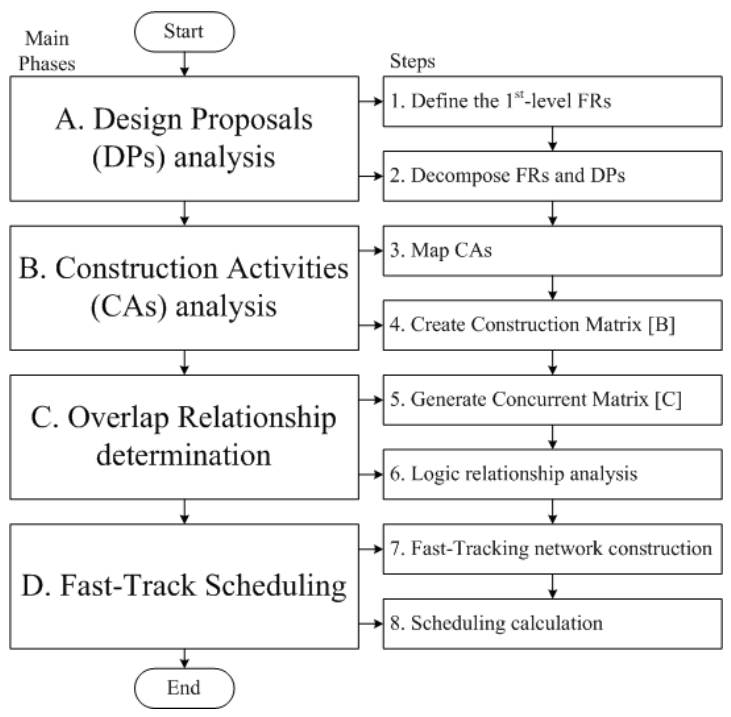

Figure 3 Procedure of the Axiomatic Design Scheduling Method

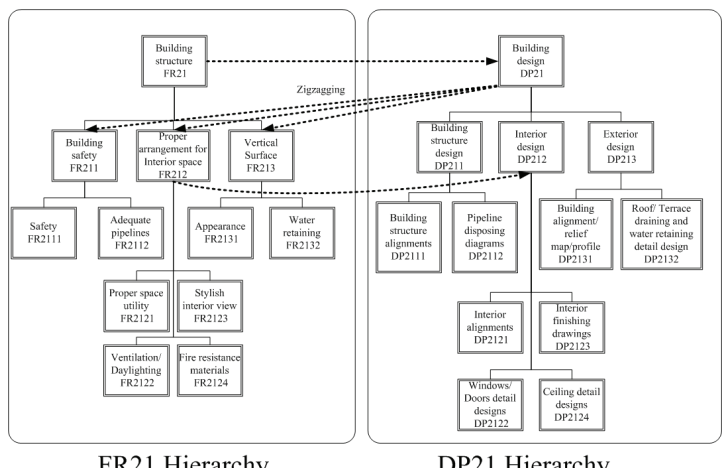

Figure 4 Zigzag Decomposition Between FR21 and DP21 within the Case Study

Table 2 Design Matrix [A] (derived from Fig. 4)

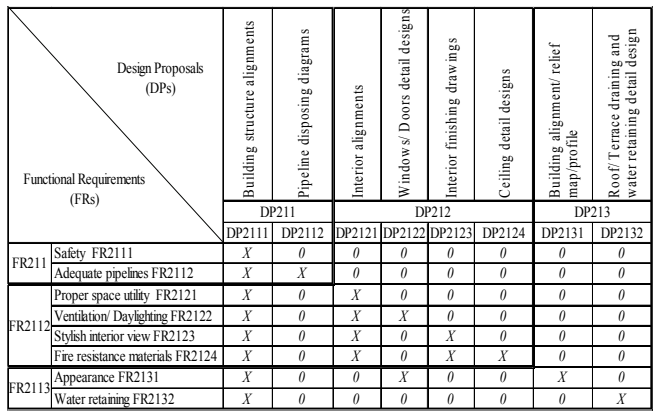

\subsection{Construction Activities (CAs) Analysis}

After the DPs hierarchy is created, the CAs corresponding to DPs and the construction matrix [B] need to determined. Unlike the zigzagging decomposition between FRs and DPs, only direct mapping from DPs to CAs is done in this step. Figure 5 shows the hierarchy of CA21 mapped from the DP21 hierarchy in Figure 4. Table 3 shows the construction matrix of DP21 and CA21.

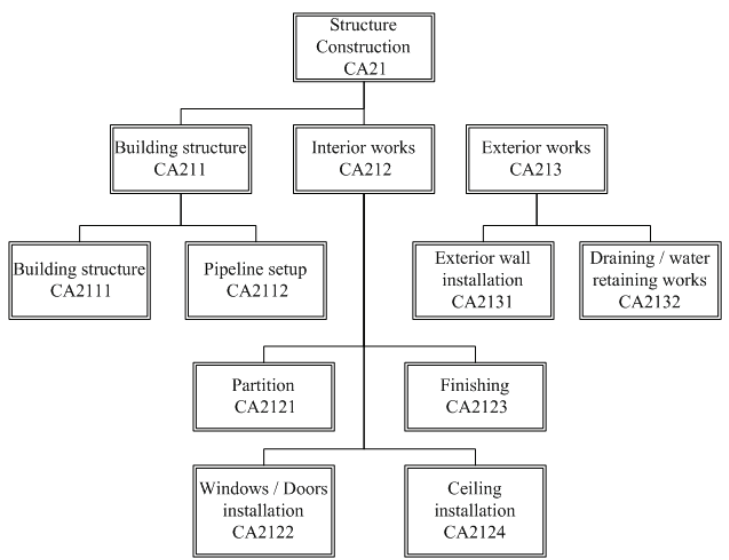

Figure 5 CA21 Hierarchy of Case Study

Once the CAs' hierarchy was created, the matrix [B] can then be generated as Table 3 shows.

Table 3 Construction Matrix [B] of CA21 of the Case Study

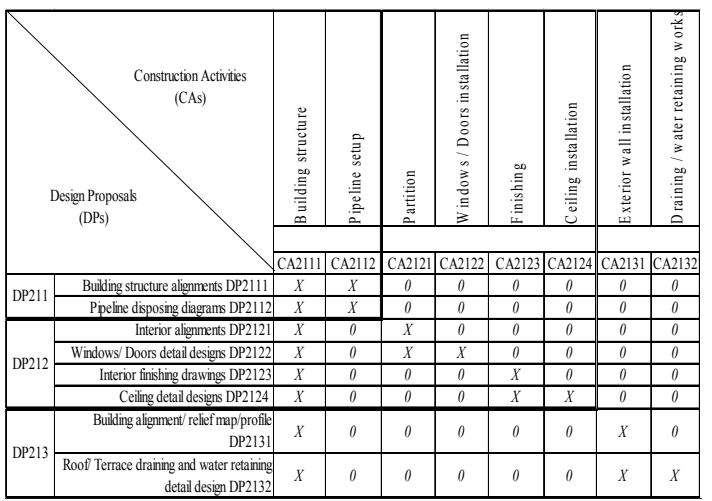

\subsection{Overlap Relationship Determination}

The primary target of this phase is to determine the overlapping relationships between each DBPs so that the fast-tracking network can be created in the next phase. Two activities should be done in this phase, namely (1) generate concurrent matrix [C], 
and (2) logic relationship analysis. First, schedule analysts can do the matrix multiplication of [A] and $[\mathrm{B}]$ matrices to generate the concurrent matrix $[\mathrm{C}]$, and subsequently, the logic overlapping relationships between each two DBPs can be determined by referring to the matrix type of [A], [B], and [C]. Table 4 shows the multiplication of design and construction matrixes respectively in Table 2 and Table 3.

\section{Table 4 Concurrent Matrix [C] of Case Study}

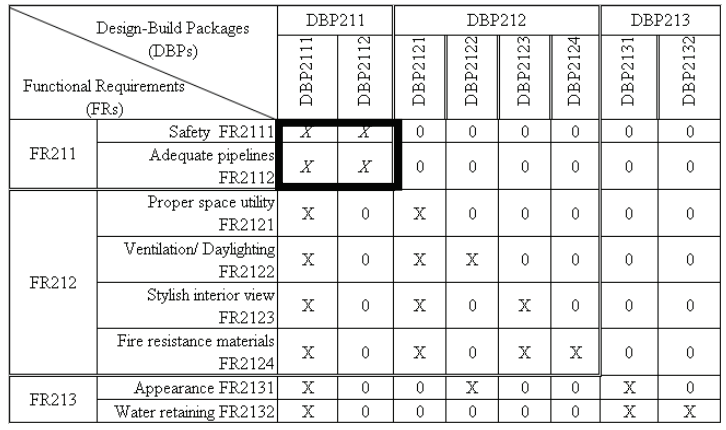

After the current matrix has been generated, the logic relationship between two DBPs can be determined in accordance with the relatedness within the matrix [C].

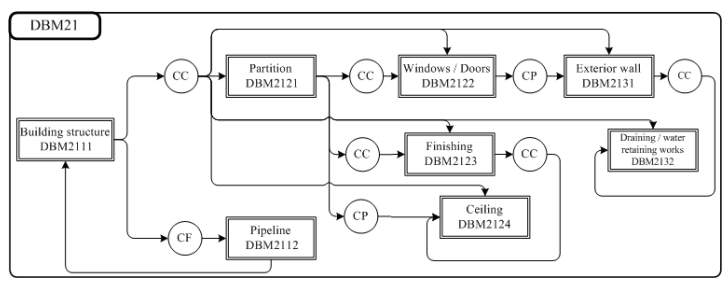

Figure 6 Fast-Tracking Diagram of Case Study

Take FR211 and FR212 in the Table 4 as an example (Black in the Table 4). FR211 and FR212 are both achieved by DBP211 and DBP212 ("full matrix" type). Furthermore, because the matrix [A] and [B] of DBP211 and DBP212 respectively in Table 2 and 3 are lower triangle matrix [LT] and full matrix $[\mathrm{X}]$, the overlap relationship between DBP211 and DBP212 is determined as the "Continuous Design \& Feedback Construction" (CF) as shown in Table 1. In the same manner, all relationships between other DBPs can be determined. Consequently, a fast-tracking diagram as shown in Figure 6 can be generated.

\subsection{Fast-Tracking Network Calculation}

According to the created fast-tracking diagram, the scheduling network can be schemed out for estimating the overlap project duration. Referred to the overlap relationships in Table 1, predecessors of each design and construction activities can be determined based on the created fast-tracking diagram. Table 5 shows an example of information predecessors and durations of activities for network calculation derived from Figure 6.

\section{Table 5 Predecessors and Durations of DPs and} CAs within the Case Study

\begin{tabular}{|c|l|l|c|}
\hline \hline S. No. & $\begin{array}{c}\text { Activit } \\
\text { y ID }\end{array}$ & \multicolumn{1}{|c|}{ Predecessors } & $\begin{array}{c}\text { Duration } \\
\text { (days) }\end{array}$ \\
\hline \hline 1 & DP2111 & - & 30 \\
\hline 2 & CA2111 & DP2111,DP2112 & 160 \\
\hline 3 & DP2112 & DP2111 & 20 \\
\hline 4 & CA2112 & DP2111,DP2112 & 80 \\
\hline 5 & DP2121 & DP2111 & 10 \\
\hline 6 & CA2121 & DP2121,CA2111 & 80 \\
\hline 7 & DP2122 & DP2121 & 5 \\
\hline 8 & CA2122 & DP2122,CA2111,CA2121 & 40 \\
\hline 9 & DP2123 & DP2121 & 5 \\
\hline 10 & CA2123 & DP2123,CA2111,CA2121 & 64 \\
\hline 11 & DP2124 & DP2121,DP2123 & 5 \\
\hline 12 & CA2124 & DP2124,CA2111,CA2123 & 64 \\
\hline 13 & DP2131 & DP2122 & 15 \\
\hline 14 & CA2131 & DP2131,CA2111 & 30 \\
\hline 15 & DP2132 & DP2131 & 10 \\
\hline 16 & CA2132 & DP2132,,CA2111,CA2131 & 20 \\
\hline
\end{tabular}

Consequently, schedule planners can construct the project schedule as shown in Figure 7. The total duration of the DPs and CAs related to the DBP21 was schemed as 418 days.

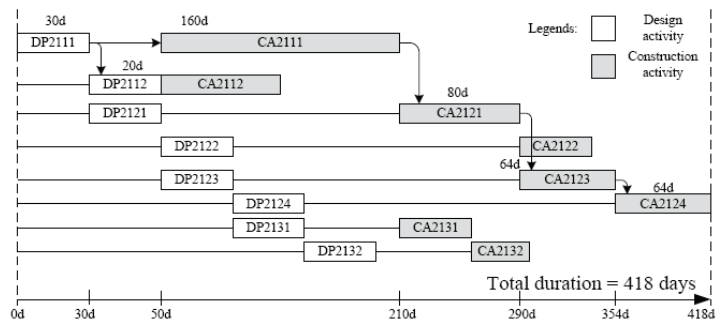

Figure 7 Duration Estimation of Fast-Tracking of Case Study

\section{DISCUSSION}

Te schedule planners can determine the shorten duration due to the overlaps of DBPs. Taking the case in Figure 7 as an example, the shorten duration of the fast-track construction can be 
calculated by comparing with the normal project duration as Figure 8 shows. Accordingly, the shorten duration caused by overlaps was determined as $438-418=20$ days.

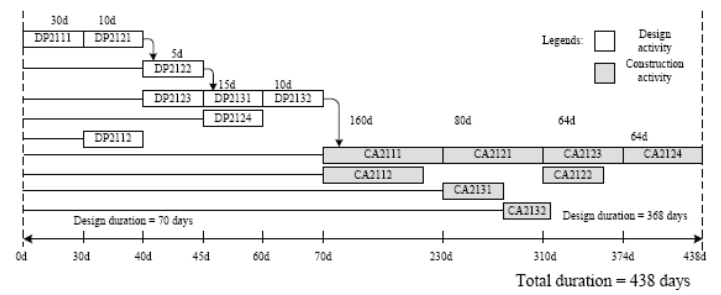

Figure 8 Estimation of Normal Project Duration

Although $\mathrm{AD}$ is a powerful method for determining the dependency relationships of design and construction jobs, the situations of resource trade-off were difficult to be considered due to increasing complexity of analysis, especially for the crew resource trade-off of design jobs. Hence, the created fast-tracking diagram presents a sequence plan but resource allocations. To overcome this situation, a resource allocation mechanism for the $\mathrm{AD}$ scheduling method is necessary in the future work to enhance the reality of the scheduling result. Accordingly, the advanced improvement for this method is proceeding, and applying to a case study of high-tech factory construction project for validate the feasibility of this concept.

\section{SUMMARY}

This study proposed a method to create a fast-tracking project schedule including design and construction activities. Based on the created method, a D/B project can be divided into DBPs by zigzagging decomposition between customer needs (CNs), function requirements (FRs), design phases (DPs) and construction activities (CAs). Meanwhile, the overlapping relationships between DBPs can be also identified in accordance with sequence information within the design matrix [A], construction matrix [B] and concurrent matrix [C]. Thus, a fast-tracking network model can be created by summarizing the DBPs and overlapping relationships. Therefore, the shorten duration raised by the fast-track construction can be evaluated by comparing with the traditional linear design and construction method. Based on the scheduling result, planners can not only realize the dependency relationships between design and construction activities, but also evaluate the time benefit of the fast-tracking delivery method for a $\mathrm{D} / \mathrm{B}$ project.

\section{REFERENCES}

[1] Peña-Mora, F., Li, M. (2001), Dynamic planning and control methodology for design/build fast-track construction projects, Journal of construction engineering and management, 127(1), 1-17.

[2] Maheswari, J.U., Varghese K. (2005). Project Scheduling using Dependency Structure Matrix, International Journal of Project Management, 23, 223-230.

[3] Kim, S. J., Suh, N. P., \& Kim, S. G. (1991). Design of software systems based on axiomatic design. Robotics and Computer-Integrated Manufacturing, 8(4), 243-255.

[4] Albano, L. D., \& Suh, N. P. (1994). Axiomatic design and concurrent engineering. Computer-Aided Design, 26(7), 499-504.

[5] Suh, N.P., Bell, A. C., \& Gossard, D. C. (1978). On an axiomatic approach to manufacturing and manufacturing systems, Journal of Engineering for Industry, 100, 127-130.

[6] Albano, L. D., \& Suh, N. P. (1992). Axiomatic approach to structural design. Research in Engineering Design, 4(3), 171-183.

[7] Bras, B., \& Mistree, F. (1993). A compromise decision support problem for axiomatic and robust design. Advances in Design Automation, 65(1), 359-369.

[8] Cheng, M.Y., Tsai, M.H. (2005). Cross-Organizational Process Integration in Design-Build Team, Proc. Of The 22th International Symposium on Automation and Robotics in Construction, Ferrara Italy. 